\title{
QіRт2008 \\ Improvement of IR-emissivity of ceramic fibre by silicon carbide coating in furnaces
}

by Imre Benko Prof.Dr.

Budapest University of Technology and Economics, Budapest, Hungary

H-1112 Budapest, Cirmos u. 1.Hungary, Fax/Phone: 36-1-310-0999, e-mail: ibenko@freestart.hu

Keywords: basic thermography, high emissivity coatings, furnaces, refractory materials, energy conservation

\begin{abstract}
The paper describes a new method which increases radiation heat transfer of furnace refractory and partly increases the gas tightness and life span of the lining. As heating-up time is decreased, the method also makes the operation of the furnace more flexible. Application of silicon carbide furnace coating increases the emissivity of ceramic fibre insulation by $45 \%$, while that of shamotte by $20 \%$. The phenomenon is illustrated by infrared thermograms and their temperature analysis. IR-emissivity $\left(\varepsilon_{n, \Delta \lambda}\right)$ was measured by infrared thermograms. Industrial applications are also referred to.
\end{abstract}

\section{Introduction}

The appearance of some new furnace construction materials, e.g. ceramic fibre insulations and high emissivity coatings (such as 'ENECOAT') requires the revision of the wall structure of some furnaces. Research was done regarding a silicon carbide $(\mathrm{SiC})$ based furnace coating. Its emissivity is considerably greater than that of the material onto which it was applied.

The basic phenomena resulting from the application of 'ENECOAT' and its thermal effects were examined in the case of several continuous furnaces of brick factories. The increase of heat radiation due to 'ENECOAT' coating of refractories decreases heat losses and results in the recuperator (cooling) part of the furnace a better cooling of brick piles and some decrease in environment pollution, too. The energy saving amounted to $4.8-6.2 \%$ and $3.8-4.4 \%$ in the case of natural gas fired and oil fired furnaces, respectively.

\section{Thermophysical data}

In the past forty years great attention has been paid to studying the emissivity of kiln linings [1],[2] and [3] as well as to energy conservation through utilisation of high emissivity coatings [4] and [5], the latter well complementing the use of low density insulating materials, such as ceramic fibres and refractory bricks [6] and [9].

The factors affecting the infrared radiation of furnace surfaces and high temperature industrial equipment have not yet been studied widely enough.

The efficiency by which materials radiate is defined as emissivity $(\varepsilon)$. Its value depends on the surface temperature and material properties of the radiating object's surface, and on the radiation wavelength $\left(\varepsilon_{n, \Delta \lambda}\right)$. It has been shown that the emissivity of refractories drops as the temperature increases. Thus, for instance, if the emissivity of a given type of a shamotte refractory brick is 0.9 at a temperature of $130{ }^{\circ} \mathrm{C}$, at $1030{ }^{\circ} \mathrm{C}$ the emissivity might well be 0.5 only (see Fig. 1. and Table 1.).

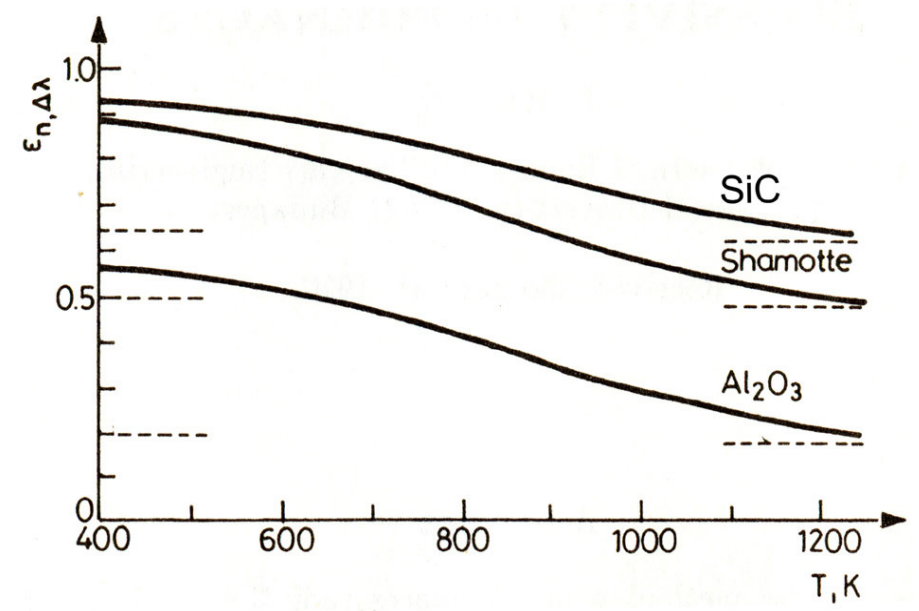

Fig. 1. Normal spectral normal emissivity $\left(\varepsilon_{n, \Delta \lambda}\right)$ of $\mathrm{SiC}$ (as ENECOAT), shamotte and ceramic fibre $\left(\mathrm{Al}_{2} \mathrm{O}_{3}\right)$ against material surface temperature 
Recent research has been focused on high emissivity coating of ceramic fibres, which increase the fibres' mechanical strength and the emitted energy. Experiments revealed that by employing a silicon carbide( $\mathrm{SiC}$ ) based coating the emissivity of a ceramic fibre can be increased to 0.63 from 0.2 at $730{ }^{\circ} \mathrm{C}$ temperature (see Fig. 1.).

Table 1. Total normal emissivity $\left(\varepsilon_{n}\right)$ of different ceramic materials

$\begin{array}{lccc}\text { Brick material } & \mathrm{t},{ }^{\circ} \mathrm{C} & \begin{array}{l}\text { Total } \\ \text { emissivity }\end{array} & \text { normal } \\ \text { Shamotte } & 20 & 0.85 \\ \text { Shamotte } & 1000 & 0.75 \\ \text { Shamotte } & 1200 & 0.59 \\ \text { Corundum } & 1000 & 0.46 \\ \text { Magnesite } & 1000-1300 & 0.38\end{array}$

Ceramic fibre insulating materials (such as $\mathrm{Al}_{2} \mathrm{O}_{3}$ ) have poor heat radiation properties (see Fig. 2.) but their insulating property is good at operating temperatures up to $1200-1400{ }^{\circ} \mathrm{C}$. However, ceramic fibre have much lower mechanical strength than traditional fireclay based materials. A recently opened way of dealing with these drawbacks is the application of a suitable coating materials. Their purpose is on one hand to improve the strength and surface properties of the ceramic fibre, and on the other hand to increase the infrared emissivity of the surface.

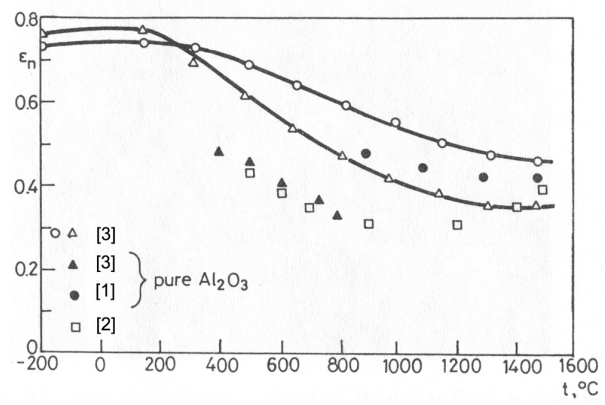

Fig. 2. Total normal emissivity $\left(\varepsilon_{n}\right)$ of different $\mathrm{Al}_{2} \mathrm{O}_{3}$ materials (in form of ceramic fibre)

\section{Test methods of IR-emissivity's measurements}

The silicon carbide based furnace coating is applied by spraying the material to a thickness of up to $1 \mathrm{~mm}$. The coating after being allowed to dry for 24 hours and then being subjected to an annealing process, forms a hard uniform layer, binding both mechanically and chemically very well the refractory beneath. Its emissivity is considerably greater then that of the material onto which it has been applied.

Application is also possible in furnaces already in use during the maintenance shut down periods. Experience shows that the coating slows down detrimental changes which occur in the chemical structure of the insulating materials, hence also erosion and wear.

As neither infrared radiation nor its effects are well understood, applied research has been carried out using a variety of refractory materials and bricks (dense and lightweight refractory block, castable refractory concrete) which are used in Hungary, as well as different types of foreign ceramic fibre (Fig. 1, and Table 1.).

The paper gives an account only of the silicon carbide effects in improving infrared emissivity $\left(\varepsilon_{\mathrm{n}, \Delta \lambda}\right)$.

\subsection{Test methods}

The infrared radiation of samples made of different insulating materials was examined in electric furnaces (Fig. 3.) at temperatures ranging from $100{ }^{\circ} \mathrm{C}$ to $1000^{\circ} \mathrm{C}$ (measured by thermocouple). 


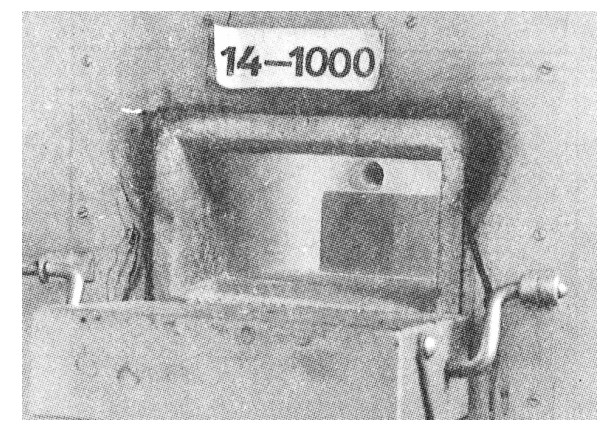

Fig. 3. One of the samples in the furnace for examination of silicon carbide effects

One half of sample was coated with silicon carbide (left side, marked with 'E': 'ENECOAT') and the other half (marked with 'R': refractory) was uncoated (see Fig. 4.).

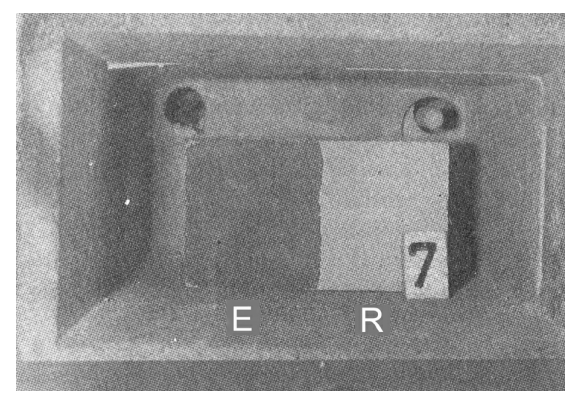

Fig. 4. Detrick $1500 \mathrm{H}$ type sample (no.7.) of ceramic fibre (marked with ' $R$ ': refractory, on the right side) and on the half part on the left is coated with silicon carbide (marked with ' $E$ ' : ENECOAT)

Infrared radiation was measured by AGA THV No.780 thermal imaging equipment. This was done by heating the sample in the furnace (see Fig. 4.) to an appropriate temperature, Then placing a shield around it (that of the surface's temperature was $20-40 \mathrm{oC}$ ) for screening it from the furnace irradiation. So the radiation of the sample could be measured without influence of the furnace's walls. The process took a few seconds and the video recording of the infrared measurements was subsequently evaluated by means of computer analysis (Fig. 5.and Fig. 6.).

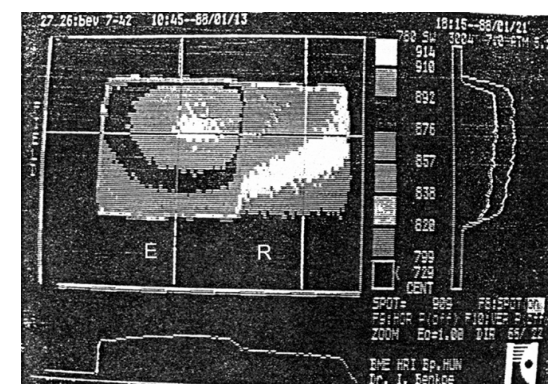

Fig. 5. The two temperature curves on the right side of the thermogram show directly how the silicium carbide coating ('E') increases the infrared emissivity of ceramic fibre ('R') (see Fig. 7., too). On the bottom part of the thermogram a 'line thermogram', temperature curve presents a 'temperature step' (emissivity difference, , $\Delta \varepsilon$ ) on the coating's boundary.(see Fig. 8.,too). 


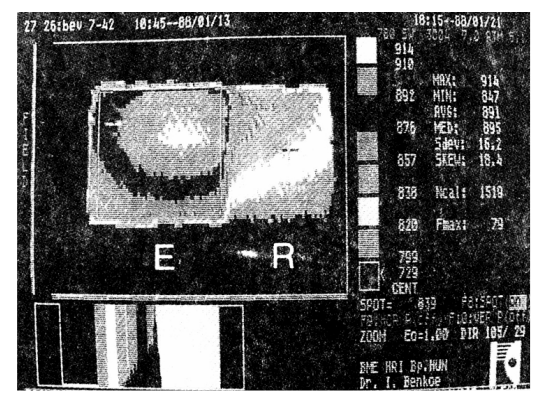

Fig. 6. Thermal image showing an uneven heat radiation's distribution and a greater infrared emissivity of the silicon carbide (histographical representation of the infrared thermogram). However the real temperature on the left and right sight of the sample is the same.

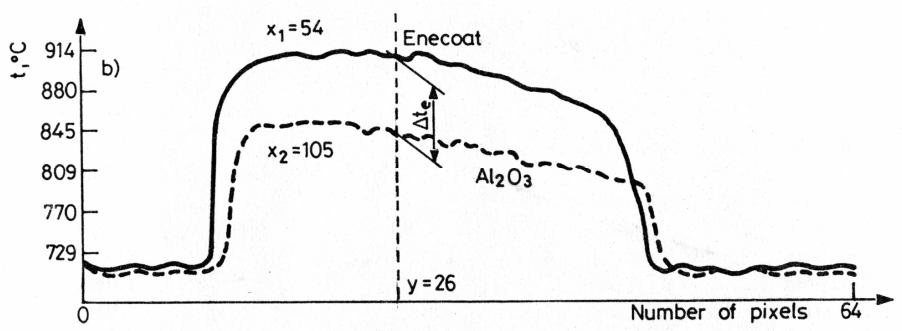

Fig. 7. One detail of Fig. 5. analysed by computer method. Temperature curves can be seen on the right side of Fig. 5. Virtual (effective) temperature difference ( $\Delta t_{\text {eff }}$ at normal spectral emissivity value equal: one $\left.\{1\}\right)$ between two sides (left and right) of sample represents the value of infrared emissivity differences (normal spectral) on the coated and uncoated surfaces.

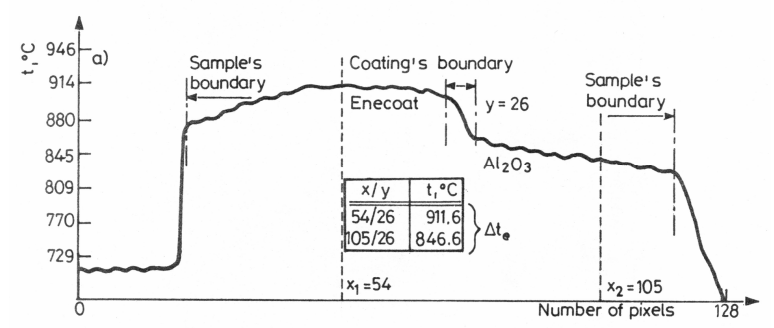

Fig. 8. Other details of Fig. 5. analysed by computer method. Temperature curve ('line thermogram') can be seen on the bottom part of Fig. 5. Virtual (effective) temperature difference on coating's boundary between two sides (left and right) of sample represents the value of infrared emissivity (normal spectral) differences on the coated and uncoated surfaces.

\section{Evaluation methods for infrared images}

The paper only covers those data obtained through the computer processing of IR-thermograms which had to be evaluated because of the IR-images gained from various measurements and the nature of the objectives.

Computer processing of the IR-images serves to speed-up considerably the evaluation of the measurements results. More important, it enable us to use methods of calculation which earlier, based on analogue pictures, were virtually impossible to employ. Examples for such calculations are the plotting of various mean temperatures and temperature distributions, the temperature histogram etc. These could not have been plotted with the required accuracy (see Figs. 5. and 6.).

Processing of digitalised IR-images may be carried out by a variety of approaches and methods. On the whole, it may be said that it is expedient to suit the strategy and the method of evaluation to the phenomenon under scrutiny. This, in some cases, calls both for heat engineering experiences and technical intuition.

In determining temperature fields of various characteristics, one may choose between the following general methods, while their relative advantages and disadvantages must be decided in the light of the test which are being done:

- the selection of the temperature interval to be tested and, within that, decision over the choice of the number and widths of the iso-strips(-bands) (see Fig. 5.),

- determining the temperature at specified points of the surface under test (e.g. in the centre point of the cross hair on Fig. $5 .:$ spot $=909^{\circ} \mathrm{C}$ at dir: $66 / 22$ pixels, see Table 2.: 1st line: location: centre), 
- a comparison between temperature distributions along the horizontal and vertical lines (e.g. two vertical temperature curves in the centre of 'E' and 'R' part of the sample no. 7. ,see Fig. 5. and Fig. 7. and one horizontal line in the middle height of the sample, see on the bottom part of Fig. 5. and Fig. 8.,also).

- determining the temperature distribution and some parameters of temperature of it in a smaller specified areas of the surface tested (e.g. on the right side of Fig. 6.: maximum, minimum, average, median, standard deviation, skewness values of the temperature distribution and ncal: number of pixels in the analysed surface, fmax: the relative height of the histogram, maximum value on the ordinate of the histogram in number of temperature's pixels ). In the centre point of ' $R$ ' part: $s p o t=839^{\circ} \mathrm{C}$ at dir: $105 / 29$ pixels (see in the Table 2.: 2nd line, location: in centre).

- statistical methods for description of the temperature distribution (see fig. 6., on bottom part and right side).

\subsection{Presentation of isotherms (iso-bands)}

On the right-hand edge of the IR-images (see Fig. 5.) can be found a colour spectrum on which the highest and lowest values of the thermal interval characteristic to a given colour band (strip, in oC ) are given where the bands join.

In the temperature field, according to a given normal spectral emissivity, in the areas which correspond to the colours, the temperatures belong in the temperature interval concerned, if the emissivity is constant in Fig. 5 . and Fig. 6. the value of the emissivity is constant and equal to one(1) for comparison the emissivity differences of 'E' and 'R' parts.

According to the previous arguments, it is very important that the iso-bands are only isotherms (isotemperatures) if the emissivity is constant along the given iso-band (strip).

\subsection{Local temperature measurements}

It is possible to carry out a local temperature measurement in image points (pixels): 8192 in the whole Fig. 5. and Fig. 6. pictures and in 1519 pixels of the selected area of the Fig. 6 . on the temperature field under scrutiny of 'E' part.

Using the horizontal and vertical co-ordinates (dir: $x ; y$ ) of the IR-image, every point of temperature's field may be determined and read at the sign 'spot' (e.g. in Fig. 5. it is $909{ }^{\circ} \mathrm{C}$ at co-ordinates $\mathrm{x}=66$ and $\mathrm{y}=22$ ). This is the maximum temperature value on the ' $E$ ' part, that is the effective temperature on silicon carbide coating in the case if the emissivity equal: $\varepsilon=1$.

It needs to be noted that on the IR-images the axis of the grid begins in the left top corner of IR-field and contains 128 image points horizontally and 64 vertically.

\subsection{Temperature distribution along straight lines}

In the temperature field one can examine the temperature distribution along lines created horizontally and vertically by image points and comparisons can be also made. Under the IR-image and on the right-hand side, respectively, temperature distribution may be displayed along three horizontal and three vertical lines of optional co-ordinates at the same time.

E.g. in Fig. 5. on the right-hand side two vertical temperature's line thermogram represent the effect of the silicon carbide coating on ceramic fibre sample and the same could be seen on Fig. 7. in detailed form. Because the own emissivity of the coating and sample are constant on the surface, so by the virtual temperature difference $\left(\Delta t_{e}\right.$, effective) could be calculate the emissivity's difference between the two materials see (Table 2.).

On the bottom part a horizontal line thermogram shows the temperature changes close by the coating's boundary stripe along a line that is positioned approximately in the middle height of the sample (detailed form of this line thermogram can be seen in Fig. 8. ).The effects of the coatings and samples boundaries and the effect of the natural convection of the air in the furnace could be observed also in this figure.

\subsection{Examining temperature distributions in selected areas}

Because sometimes we need a smaller part of the whole IR-thermogram so it is expedient to select areas on the basis of technical consideration, and to submit the temperature values measured there to so-called histographic processing. For this purpose, we displayed on the vertical axis the number of image points where a certain temperature was measured as a function of the temperatures measured in a certain area (horizontal axis).

The histogram so obtained can be found under the IR-picture field, where the temperature values of the colour spectrum correspond to those described on the part of paragraph 4.1: 'Presentation of isotherms', which are described above, The value representing the height of the histogram is the number of that temperature which is present the highest number of image points. This is represented by the 'fmax' value which is the last of the data given by the right-hand edge of the IR-image.

Of the more significant values characteristic of the histograms, the following are given in Fig. 6. according to the 4.paragraph. In the area marked by a rectangle around the silicon carbide coated surface (in Fig. 6 . ' $E$ ' part on the left): the highest temperature - $\max =914^{\circ} \mathrm{C}$, the lowest temperature $-\min =847^{\circ} \mathrm{C}$, and the mean temperature $-\operatorname{avg}=891^{\circ} \mathrm{C}$ in the field under scrutiny. The other significant values of the histogram under analysis: 
the median, the temperature in the middle part of the temperature interval - med $=895^{\circ} \mathrm{C}$, the standard deviation $\mathrm{sdev}=16.2 \mathrm{~K}$, the skewness value of the distribution - skew $=18.4$, the ordinate of the histogram in number of temperature's pixels - fmax $=79$ pixels. The number of pixels in the histographic analysis of the 'E' part $n \max =1519$ pixels.

\section{Examination of IR-emissivity of different materials}

In the recent years using IR-cameras for IR-thermogrammetry a great attention has ben paid to studying the emissivity of different materials in the spectrum of the IR-cameras. The method used in our study was one of the direct comparative type in which the IR-radiations' intensity received by an infrared imaging equipment from a heated specimen was used to determine the normal spectral emissivity of material under scrutiny. The half of each sample was coated by different material's coatings under testing, while the other half of the specimen was uncoated.

The measuring method consists of two consecutive steps. In the first step the IR-imaging equipment, which viewed the sample at right angles to the surface of the specimen, received both the radiation emitted by the specimen and the environment radiation (e.g sun or furnace) reflected from it. In the second step, the sample shielded from the environmental radiation, so the IR-imaging equipment received only the radiation emitted by a non-uniform heated coated and uncoated sides of the sample. If the temperature field is constante and homogeneous, the emitted radiations measured from the coated and uncoated side correspond to a virtual temperature of each side if the emissivity value during the image taking process is equal: $\varepsilon=1$. Numeric values for the temperature represent the so-called effective black body temperature. The process took a few seconds and the video recording of the infrared measurements was subsequently evaluated with computerised analysis.

\subsection{Emissivity of ceramic fibre}

In the presented test (Fig. 4.) the material that of the normal spectral IR-emissivity is known, was Detrick No. $1500 /$ CF 1500 , a hard, white, vacuum formed ceramic fibre with a density of $320 \mathrm{~kg} / \mathrm{m}^{3}$ and suitable for temperature up to $1500^{\circ} \mathrm{C}$. The temperature of the material (ceramic fibre) was measured by a thermocouple placed in the surface, and the so-called black body temperature of the radiating surface provided the basis for calculating the surface emissivity. Calculation showed the surface emissivity of the fibre to be 0.498 at $1060^{\circ} \mathrm{C}$ furnace temperature.

\subsection{Comparison calculation of emissivities}

A method was worked out to evaluate the temperature field on the surface of the samples and for calculating the emissivity at certain temperatures [5], [8]. The general equation between temperatures and emissivities comes from the next equation.

So from Equation (1) it follows that:

$$
\sigma . \mathrm{T}_{1}^{4} \cdot \varepsilon_{1}=\sigma . \mathrm{T}_{2}^{4} \cdot \varepsilon_{2} \text {. }
$$

$$
\varepsilon_{1} / \varepsilon_{2}=\left(T_{2} / T_{1}\right)^{4} \text {. }
$$

\subsection{Comparison of surfaces with different emissivities}

The surface emissivity of the Detrick ceramic fibre $1500 \mathrm{H}$ was compared with that of Enecoat (Fig. 4.).

In Fig. 5. , two vertical and one horizontal line across the thermogram mark the cross-section on the sample,for which temperature distribution was computed. The three temperature distribution curves are plotted in the right-hand side and bottom of Fig. 5.for the respective cross-section, and redrawn in a graph in Figs. 7. and Fig. 8. The temperature between the two curves in Fig. 7. is nearly constant at about $\Delta \mathrm{t}_{\mathrm{b}}=65-70 \mathrm{~K}$ (black body temperature difference). This is the difference between the area coated with Enecoat and the uncoated surface and shows that the Enecoat directly increases the infrared emissivity of the material, namely of the Detrick ceramic fibre. Numeric values for the temperature represent the so-called 'effective black body temperature'.

\begin{tabular}{|c|c|c|c|c|}
\hline No.line & Topics & $\begin{array}{l}\text { Location } \\
\text { centre }\end{array}$ & boundary & Average values \\
\hline $\begin{array}{l}3 . \\
4 . \\
5 . \\
6 .\end{array}$ & 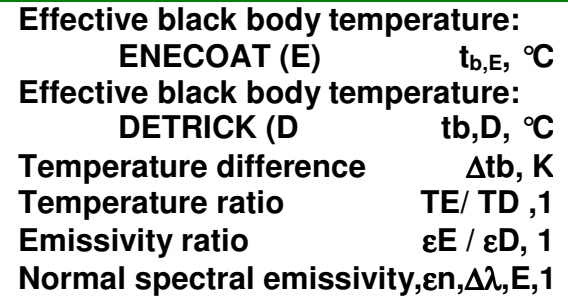 & $\begin{array}{r}909 \\
\\
839 \\
70 \\
1.053 \\
1.27 \\
0.63\end{array}$ & $\begin{array}{l}910 \\
\\
876 \\
34 \\
1.030 \\
1.12 \\
0.56\end{array}$ & $\begin{array}{r}891 \\
836 \\
55 \\
1.0496 \\
1.21 \\
0.6\end{array}$ \\
\hline
\end{tabular}

Table 2. Calculation of ENECOAT's normal spectral emissivity $\left(\varepsilon_{n, \Delta \lambda, E}\right)$ at $1060^{\circ} \mathrm{C}$ furnace temperature 


\subsection{Calculation of data in Table 2.}

It needs to be noted that the data comes from the Fig. 5. and Fig. 6.are adequate values because the real thermal and thermophysical circumstances of the sample's coated and uncoated surfaces was applied.. So additive effects of the natural convection (heat transfer) of the air can be seen on Figs. 5 . and 6 . as some asymmetry of temperature field. For example in the left side on Fig. 5. the position of the greater temperature is a bit of higher as in the middle point of it (see Fig. 7.,too).

In Table 2. the data in line 1. and 2. come from the Fig. 5.and Fig.6. (see 4.paragraph). In Fig. 8. same data can be seen in the smaller table of the middle position of the table, so $\Delta T_{e}=\Delta T_{b}=\left(t_{b E}-t_{b D}\right)=65 \mathrm{~K}$. Fig. 7 . presents two temperature distributions in abscisses: $x_{1}=54$ and $x_{2}=105$ pixels. On the other hand In Fig. 8. one curve is presented in ordinate: $y=26$ pixels. This configuration gives us a good overview about the whole temperature field on the sample.

The sense of the parameters and indexes in Table 2. are the follows:

$\sigma, \mathrm{W} / \mathrm{m}^{2} \mathrm{~K}^{4}$, the Stefan-Boltzmann constant,

$\varepsilon_{b}=1,1$, emissivity on black body temperature (virtual), adjusted value of the IR-camera,

$\varepsilon_{D}, 1$, surface emissivity of a Detrick's sample, $\varepsilon_{D}=0.498$,

Indexes:

b , eff, e, effective black body,

$\mathrm{E}$, Enecoat coating material silicon carbide, $\mathrm{SiC}$,

$\mathrm{D}$, Detrick ceramic fibre insulating material, $\mathrm{Al}_{2} \mathrm{O}_{3}$,

$\mathrm{f}$, sample's real temperature in the furnace, $\mathrm{T}_{\mathrm{f}}=1060{ }^{\circ} \mathrm{C}$,

$\mathrm{n}, \Delta \lambda$, normal spectral value of the emissivity.

Table 2. shows that the Enecoat's emissivity $\varepsilon_{\mathrm{n}, \Delta \lambda, \mathrm{E}}$ at $1060{ }^{\circ} \mathrm{C}$ reaches values in the range 0.63 to 0.56 on the examined sample, and that the infrared radiation has increased by 12 to $27 \%$.

\section{Industrial application for energy saving of continuously working furnace}

For the calculation of heat losse of a surface, in steady state conditions we have to known the wall temperature with appropriate accuracy. Connection between the average wall temperature (tavg) and heat loss $(\mathrm{Q})$ is given by the following equation:

$$
Q^{\bullet}=\sum_{i=1 \rightarrow n} A_{i} \alpha_{i}\left(t_{a v g}-t_{e n v}\right) \text {. }
$$

where

$A_{i}, m^{2}$, a selected minor area $(i=1 \rightarrow n)$ of the measured surface,

$\alpha_{i}, W / m^{2} K$, the coefficient of heat transfer and emissivities constant,

$t_{\text {env }},{ }^{\circ} \mathrm{C}$, the temperature of environment.

So the values of temperature distribution in a selected area very important for the determination of heat loss and other practical calculations.

\subsection{Case study: a brick and tile works}

Under our research work concerning the practical implementation of the R\&D findings of silicon carbide lining material, we decided to line a continuously working furnace of the Brick and Tile Works in Hungary and to carry out an evaluation of the results in the field of energy and thermal engineering.

The Faculty of Mechanical Engineering was appointed by the Company, and we took part in the preparation, execution and control of the practical implementation of project in the Sopron Brick Works in Hungary. We examined the thermal conditions of the furnace before and after the 'ENECOAT' treatment, carried out thermal engineering test on the burnt clamps of bricks and examined the mechanism which causes lining with 'ENECOAT' to increase infrared radiation.

\subsection{Objectives}

Owing to the large size of the exterior surface of the continuously working furnace as well as the sectional layout of the clamps, it was expedient to employ the infrared imaging equipment. It made it possible to receive a good and thorough overview of all these surfaces, as well as the periodically changing temperature distribution on the clamps. It is to be noted that these operational measurements in no way disturbed production or distorted the normal pace of operation. Examination of the surfaces described in the foregoing was carried out continuously and the data was recorded on IR-video which makes it possible to refer back to them.

\subsection{Test circumstances}

The two condition measurements taken before and after applying 'ENECOAT' treatment was preceded by repeating several times local data taking and information measurements.

The refractory part of the continuously working furnace is $126 \mathrm{~m}$ long. This length comprises a $42 \mathrm{~m}$ preheating section, a $35 \mathrm{~m}$ firing zone and a $49 \mathrm{~m}$ long cooling zone. The inner dimensions of the furnace are: width $3.4 \mathrm{~m}$, useful height $1.8 \mathrm{~m}$. This makes the useful interior surface of the furnace $882 \mathrm{~m} 2$. 
Of the whole length of the furnace, lining was applied, in two layers of 'ENECOAT', over a $26.6 \mathrm{~m}$ section of the firing zone, as well as a section corresponding to the total lenght of two carriages $(2 \times 2.85 \mathrm{~m})$ of the preheating zone, altogether $32.3 \mathrm{~m}$ in length, i.e. $226.1 \mathrm{~m} 2$ of the entire interior surface. This means roughly $26 \%$ of the total interior surface of the furnace.

\subsection{Examining temperature distribution in furnace sidewall}

Because of the surface relating to the continuous furnace tests are extensive, it is expedient to select areas on the basis of technical considerations, and to submit the temperature values measured there to so called histographic processing (Fig. 9.). For this purpose, we displayed the number of image points where a certain temperature was measured, on the vertical axis, as a function of the temperatures measured in a certain area (horizontal axis). The histogram so obtained can be found under the isotherm field where the temperature values of the colour spectrum correspond to those described on the isotherms which are described above. The value representing the height of the histogram is the number of that temperature which is present the highest number of image points. This is represented by the 'fmax' value which is the last of the data given by the right-hand edge of the IR-image.

\subsection{Measurement results of furnace sidewall}

The results of measurements made on the sidewall of the furnace before and after lining with 'ENECOAT' (see Fig. 9.), are presented in Table 3. and summarized in the Table 4.

Table 3. Data of IR-thermograms and histograms (Fig.9.) on the furnace sidewalls before and after the lining of interior surface

\begin{tabular}{|c|c|c|c|}
\hline No.line & Topics & \multicolumn{2}{|c|}{$\begin{array}{l}\text { Before } \\
\text { of the lining with } \\
\text { 'ENECOAT' of interior } \\
\text { surfaces }\end{array}$} \\
\hline 1. & Highest temperature, 'max', ${ }^{\circ} \mathrm{C}$ & 82.5 & 83.9 \\
\hline 2. & Lowest temperature, 'min' , ${ }^{\circ} \mathrm{C}$ & 57.5 & 45.5 \\
\hline 3. & Mean temperature, 'avg', ${ }^{\circ} \mathrm{C}$ & 69.5 & 61.3 \\
\hline 4. & Median temperature, 'med', ${ }^{\circ} \mathrm{C}$ & 63.5 & 61.0 \\
\hline 5. & $\begin{array}{ll}\text { Standard } & \text { deviation } \\
\text { temp.difference,'sdev',K} & \end{array}$ & 3.8 & 6.8 \\
\hline 6. & Skewness, 'skew', 1 & 4.5 & 8.2 \\
\hline 7. & $\begin{array}{l}\text { Maximum ordinate } \\
\text { histogram,'fmax', pixels }\end{array}$ & 397 & 277 \\
\hline 8. & $\begin{array}{llll}\text { Max. pixels' } & \text { number } & \text { in } \\
\text { histogram,'ncal',pixels } & & \\
\end{array}$ & 2611 & 2749 \\
\hline 9. & $\begin{array}{l}\text { Temperature in 'spot' ( 'dir' } \mathrm{x} / \mathrm{y} \text {, pixels), } \\
{ }^{\circ} \mathrm{C}\end{array}$ & $82.5(9 / 33)$ & $57.7(71 / 32)$ \\
\hline 10. & Normal spectral emissivity, $\varepsilon_{n, \Delta \lambda}, 1$ & 0.93 & 0.93 \\
\hline
\end{tabular}

Table 4. Conclusion of the silicon carbide lining of the furnace's interior surface

\begin{tabular}{|l|c|c|}
\hline \multicolumn{1}{|c|}{ Sidewall of furnace } & before & \multicolumn{2}{c|}{ after } \\
& \multicolumn{2}{|c|}{ the lining of interior surfaces } \\
\hline Mean temperature on the exterior surface, ${ }^{\circ} \mathrm{C}$ & $69.4-66.6$ & $61.3-57.9$ \\
\hline Thermal bridge temperature, ${ }^{\circ} \mathrm{C}$ & $84.5-82.5$ & $89.9-79.0$ \\
\hline Min. temperature on the insulated surface, ${ }^{\circ} \mathrm{C}$ & $57.5-50.1$ & $46.5-39.6$ \\
\hline
\end{tabular}

These results indicate that, after lining the interior surface with 'ENECOAT', the mean and minimum temperatures of the exterior surface fall. On the other hand, the temperature of the thermal bridges rose because the application of 'ENECOAT' lining increased the temperature on the interior surface of the furnace. On the whole, the lining had a favourable effect on the temperature field of the sidewall of the furnace. 


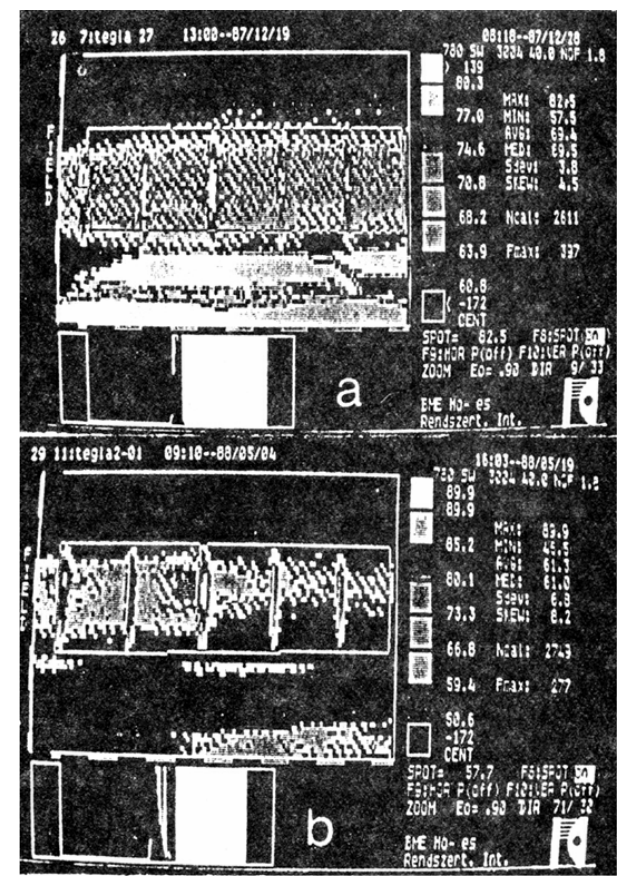

Fig. 9. IR-thermograms and histograms on the sidewalls of the furnace before (a), and after lining(b) of the

\section{Conclusion}

interior surfaces.

Both direct thermal engineering measurements and calculations in energetics prove that the specific gas consumption of the continuous furnace fell by $4.8-6.2 \%$, following the lining of the interior surfaces of the firing zone with 'ENECOAT'.

Examination of 'ENECOAT' applied to a range of Hungarian refractory materials continues within the framework of the National Research Project. According to the current findings, it appears that application of the 'ENECOAT' is also beneficial in case of silicate-based refractory materials, too.

\section{REFERENCES}

[1] J.R.Pattison: The total emissivity of some refractory materials above $900{ }^{\circ} \mathrm{C}$, Trans. Brit. Ceram. Soc., Vol.54 (1955) pp.698-705.

[2] I.E.Kempbell: Technika visokih temperatur (in Russian), Izd. inostr. lit., Moscow (1959).

[3] A.Goldsmith, T.E.Waterman and H.J.Hirschhorn : Handbook of thermophysical properties of solid materials, Pergamon Press,Oxford $(1961,1963)$.

[4] Inst. of Energy,London: Ceramics in energy applications, Adam Hilger.Bristol and New York(1990).

[5] I.Benko: Energy conservation through increased emissivity in furnaces, Periodica Polytechnica, Budapest ,Ser:Mech.Eng.,Vol.35 (1991), No.4, pp.235-245.

[6] I.Benko: Industrial application and effects of 'ENECOAT' to increase surface emissivity, ENCONET Newsletter (UNDP/UNIDO , Project Industrial Energy Conservation Network), Prague, Vol.3 (1991), No.1.pp.3-8.

[7] I.Benko: Application of infrared thermogrammetry in thermal engineering, Quantitative Infrared Thermography (QIRT 92), Eurotherm Series, No.27 (1992).Editions Européenne Thermique et Industrie,Paris, pp.343-349.

[8] I.Benko: Examination of low emissivity coatings by infrared imagery, Advanced Infrared Technology and Applications (I.R.O.E. del C.N.R.), Ed..Grafiche Troya, Florence(1993), pp.185-197.

[9] I.Benko: High infrared emissivity coating for energy conservation and protection of inner surfaces in furnaces, Int. J. Global Energy Issues, Vol.17,Nos. 1/2, Geneva (2002),pp.60-67. 
http://dx.doi.org/10.21611/qirt.2008.06_02_08 